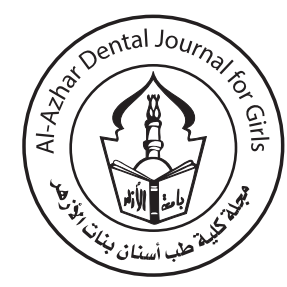

\title{
Marginal Accuracy and Microleakage of Machinable Laminate Veneers
}

\author{
Heba I. Ahmed ${ }^{1 *}$, Eman A. Essam², Osama Saleh², Walaa O. EI Mekkawi ${ }^{3}$
}

Codex : 30/2004

azhardentj@azhar.edu.eg

http://adjg.journals.ekb.eg

DOI: 10.21608/adjg.2020.14158.1181

Restorative Dentistry

(Removable Prosthodontics, Fixed

Prosthodontics, Endodontics, Dental Biomaterials, Operative Dentistry)

\section{KEYWORDS}

E-max,

Vita Suprinity,

Reinforced ceramics,

Microleakge.

\begin{abstract}
Purpose: The current study aimed to evaluate the marginal accuracy and microleakage of machinable laminate veneers. Materials and Methods: Twentyfour human maxillary central incisor teeth were collected and prepared (butt-joint preparation) to receive laminate veneers. They were divided into three groups $(n=8)$ according to material of construction: Group I: IPS-Emax CAD, Group II: Vita Suprinity, Group III: Celtra-Duo. The veneers were milled from the blocks in a CEREC 3 Machine. All veneers were cemented with resin cement. All samples had been subjected to 1500 thermal cycles which are equivalent to one year and half of clinical use. Marginal gap (pre and post cementation) and microleakage were detected for all samples. Data were tabulated and statistically analyzed. Results: Regarding vertical marginal gap, E max CAD showed the highest mean value followed by Celtra Duo, while the lowest mean value was found in Vita Suprinity. The mean values before cementation were higher than after cementation. Regarding microleakage, the highest mean value was found in E max followed by Celtra Duo, while the lowest mean value was found in Vita Suprinity. Leakage at cervical margins showed higher mean values than incisal one. Conclusion: Under the test conditions, the following was concluded: Zirconia reinforced Lithium silicate restorations, particularly the partially crystalline form, introduced better marginal accuracy and microleakage than Lithium disilicate restorations. There is a direct correlation between marginal accuracy and microleakage.
\end{abstract}

\section{INTRODUCTION}

Laminate veneers, since their introduction in 1983, have been considered one of the most feasible treatments ${ }^{(1)}$. Practicing dental

- Paper extracted from Master thesis titled "Marginal Accuracy and Microleakage of Machinable Laminate Veneer"

1. Dentist at Ministry of Health, Egypt

2. Professor of Crowns and Bridges, Faculty of Dental Medicine for Girls, Al-Azhar University, Cairo, Egypt.

3. Lecturer of Crowns and Bridges, Faculty of Dental Medicine for Girls, Al-Azhar University, Cairo, Egypt

* Corresponding author email: dr_oba@hotmail.com 
aesthetic restorations in a conservative way is very important ${ }^{(2)}$. For that, there is continuous updating in restorative materials and the used techniques, to provide both the patient and the dentist esthetic requirements in a least invasive or noninvasive way ${ }^{(3)}$. Porcelain veneers showed durability more than that of composite veneers. Several changes have been evolved in dental ceramics including their chemical composition, manufacturing processes, esthetic properties and indications ${ }^{(4)}$.

Glass ceramics showed general improvement in their mechanical and physical properties, that makes them ideal to be used as a dental restorative material ${ }^{(4)}$. The glass matrix is highly filled by micron-sized crystals of leucite or lithium disilicate $^{(5)}$.

Ceramics reinforced by lithium disilicate (e.g, IPS e.max) are true glass ceramics, with $70 \%$ refined sized crystal amount to improve flexural strength. It can be used as an esthetic monolithic restoration and can be used as laminate veneers or as a core material, because of its high translucency with availability in different shades ${ }^{(6)}$.

New additions are zirconia-reinforced lithium silicates (ZLS) (eg, Celtra Duo, Vita Suprinity). ZLS composed of lithium-silicate glass ceramic that is strengthened with approximately $10 \%$ zirconia crystals. Vita Suprinity, introduced in a partially crystalline form and exhibits its final esthetic and physical properties only after final crystallization in a specialized dental furnace (Vita), unlike Celtra duo which introduced in a fully crystalline stage with no need to the crystallization step ${ }^{(7)}$.

Inaccurate margin create spaces between the margin of restoration and the prepared tooth surface. Disturbance in the marginal accuracy can create stress concentrations that reduce the strength of the restoration and causes its fracture ${ }^{(8)}$. Some authors said that the margin of the restoration is considered clinically accepted when the marginal gaps and cement thicknesses is $<120 \mu \mathrm{m}$. Different testing techniques and methods have been used to evaluate the marginal accuracy including direct microscope, cross sectional views, light bodied impression replica, laser videography using light bodied impression replica, profilometry and $\mathrm{X}$ ray micro-tomography which viewed $2 \mathrm{D}$ and $3 \mathrm{D}$ imaging of the space between the tooth/model die and restoration ${ }^{(9)}$.

Marginal integrity directly affects the microleakage, as any discrepancy leads to cement dissolution and microleakage ${ }^{(10)}$.

In the case of all ceramic restorations, different in vivo and in vitro tests have been used to evaluate microleakage around restoration. The commonly accepted technique of evaluation for marginal integrity is the in vitro microleakage evaluation. Such in vitro studies include the use of tracers like dyes, radioactive isotopes, chemical tracers and bacteria, marginal percolation of water and subjection to air pressure, neutron activation analysis (NAA), scanning electron microscope and electrical conductivity ${ }^{(12,13)}$. The most commonly used method is the dye penetration because of its simplicity. Penetration of dyes involves the sectioning of teeth with sawing equipment then the microscope is used to evaluate dye penetration as it processes a software program that was designed to measure the length of the penetration ${ }^{(14)}$.

\section{MATERIAL AND METHODS}

In this study twenty- four human maxillary central incisors were collected and prepared to receive laminate veneers. They were divided into three groups $(n=8)$ according to material of construction: Group I: IPS-E max CAD, Group II: Vita suprinity, Group III: Celtra Duo.

\section{Sample preparation:}

All samples were prepared for a butt-joint preparation with labial depth of $0.5 \mathrm{~mm}, 0.3 \mathrm{~mm}$ cervical and $2 \mathrm{~mm}$ incisal reduction. To standardize the amount of reduction; silicon index was made 
to be used as template to evaluate the amount of tooth reduction. A three wheel depth cutter diamond stone guided the reduction. Any sharp angles were removed to prevent stress concentration.

\section{Scanning of the preparations:}

All prepared teeth were scanned by using in-lab software version 3.8 (Sirona, Germany). A CAD/ CAM milling machine had been used to mill the ceramic blocks (in Lab MCXL ,Sirona, Germany). The veneers were seated and cemented with resin cement (RelyX veneer cement, 3M ESPE, USA).

\section{Marginal gap measurements:}

Each specimen was photographed using universal serial bus (USB) digital microscope (Guangdong, China) with a built-in camera connected with an IBM compatible personal computer using a fixed magnification of $90 \mathrm{X}$. Shots of the margins were taken for each specimen. Four equidistant landmarks along the cervical and incisal circumferences for each surface of the specimen (mesial, labial, distal, and incisal) were done. Each selected point was measured and repeated five times. The measures were done before and after cementation of all specimens. The data collected, tabulated and statistically analyzed.

\section{Thermal cycling procedure:}

All samples were subjected to 1500 thermal cycles, equivalent to 1 year and half of oral service $^{(15)}$. Dwell times were 25 seconds in each water bath. The low-temperature point was $5^{\circ} \mathrm{C}$. The high temperature point was $55^{\circ} \mathrm{C}$.

\section{Microleakage measurements:}

All the teeth were placed in $2 \%$ methylene blue solution (Supreme organization for drugs, Germany) for 24 hours at room temperature $\left(37^{\circ} \mathrm{C}\right)$ using an incubator, then rinsed thoroughly with distilled water. Then the roots of teeth were removed using a diamond cutting disk (Isomet 4000 saw Buehler USA )till 2mm beyond the cementoenamel junction.

The laminates and the crown portions of the teeth were submerged into clear acrylic resin (Acrostone, WHW plastic, England) to avoid chipping of the laminates during testing procedures.

Using diamond cutting disk of 4-inch diameter and $0.3 \mathrm{~mm}$ thickness (Isomet 4000 saw, Buehler, USA), the teeth were sectioned labio-palatally into 2 equal halves.

Each half was evaluated for microleakage under stereomicroscope (Nikon MA stereomicroscope, Japan, with 50X magnification) attached to a microscopic camera by which the image was captured and then transferred to a computer equipped with the image analysis software program (Omnimet, Buehler, USA).

\section{RESULTS}

The mean and standard deviation values were calculated for each group in each test. Data were explored for normality using Kolmogorov-Smirnov and Shapiro-Wilk tests; data showed parametric (normal) distribution.

Paired sample t-test was used to compare between two groups in related samples. One-way ANOVA followed by Tukey post hoc test was used to compare between more than two groups in nonrelated samples. Two-way ANOVA was used to test the interaction between different variables.

\section{Vertical marginal gap assessment:}

\section{Total effect of material on marginal gap regard- less to cementation}

A statistically significant difference was found between (Group I), (Group II) and (Group III) .

The highest mean value was found in (Group I), followed by (Group III), while the lowest mean value was found in (GroupII), Table(1) and figure(1). 


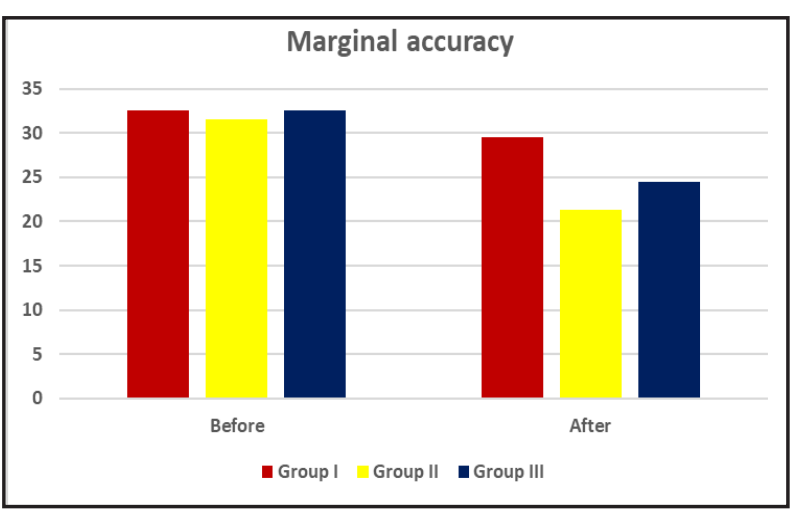

Figure (1) Bar chart representing the effect of material on vertival marginal gap distance

Total effect of cementation on marginal gap regardless to material

A statistically significant difference was found between (Before) and (After).

The highest mean value was found in (Before), while the lowest mean value was found in (After), Table (1).

Table (1): The mean, standard deviation (SD) of vertical marginal gap in different materials groups before and after cementation.

\begin{tabular}{|c|c|c|c|c|c|}
\hline \multirow{2}{*}{ Variables } & \multicolumn{5}{|c|}{ Vertical marginal gap } \\
\cline { 2 - 5 } & \multicolumn{2}{|c|}{ Before } & \multicolumn{2}{c|}{ After } & \multirow{2}{*}{ P-value } \\
\cline { 2 - 6 } & Mean & SD & Mean & SD & \\
\hline Group I & 32.61 & 0.80 & 29.58 & 0.64 & $0.015^{*}$ \\
\hline Group II & 31.58 & 1.51 & 21.33 & 2.07 & $0.011^{*}$ \\
\hline Group III & 32.56 & 2.10 & 24.52 & 1.42 & $0.007^{*}$ \\
\hline P-value & $0.595 \mathrm{~ns}$ & $<0.001^{*}$ & \\
\hline
\end{tabular}

*; significant ( $p \leq 0.05) n s ;$ non-significant $(p>0.05)$

\section{Microleakage assessment:}

\section{Total effect of material type regardless the measurement site}

A statistically significant difference was found between (Group I), (Group II) and (Group III).
The highest mean value was found in (Group I) followed by (Group III), while the lowest mean value was found in (Group II), Table (2).

\section{Total effect of measurement site regardless the material type}

A statistically significant difference was found between (Incisal) and (Cervical).

The highest mean value was found in (Cervical), while the lowest mean value was found in (Incisal), Table (2).

Table (2): The mean, standard deviation (SD) of microleakage in different materials groups at incisal and cervical margins.

\begin{tabular}{|c|c|c|c|c|c|}
\hline \multirow{2}{*}{ Variables } & \multicolumn{5}{|c|}{ Microleakage } \\
\cline { 2 - 5 } & \multicolumn{2}{|c|}{ Incisal } & \multicolumn{2}{c|}{ Cervical } & \multirow{2}{*}{ P-value } \\
\cline { 2 - 5 } & Mean & SD & Mean & SD & \\
\hline Group I & 146.875 & 9.819 & 269.500 & 8.194 & $<0.001 *$ \\
\hline Group II & 118.500 & 9.725 & 121.000 & 6.234 & $0.614 \mathrm{~ns}$ \\
\hline Group III & 96.500 & 5.425 & 198.250 & 7.630 & $<0.001 *$ \\
\hline P-value & \multicolumn{2}{|c|}{$<0.001 *$} & $<0.001 *$ & \\
\hline
\end{tabular}

*; significant $(p \leq 0.05) n s$; non-significant $(p>0.05)$

\section{DISCUSSION}

The present study examined the marginal accuracy pre and post cementation and microleakage of the laminate veneers after thermocycling on three CAD/CAM ceramic materials by using one preparation design (butt joint). Thermal cycling procedure is a method to simulate intraoral conditions. Its performance as clinical trials are costly and time consuming ${ }^{(16,17)}$.

For marginal gap consideration, Irrespective of the material, it was found that the vertical gap distance after cementation is significantly lower than before cementation. That was not in conformity 
with some studies that have reported an increase in the marginal discrepancy following cementation with either resin-modified glass ionomer or resin cement ${ }^{(18,19)}$. This decrease in the marginal gap after cementation in the current study may be related to the cement space that was created during veneer designing allowing the cement to flow without affecting the marginal adaptation of the veneer, in addition of using low viscosity Rely $\mathrm{X}$ veneer cement that was specifically designed to allow the veneer to be seated completely to the margins without the risk of fracture. Its unique "nonslumping" nature allows the veneers to be placed easily without drifting or slumping. Unlike high viscosity resin cements that may lead to limited time of penetration and a thick layer of cement if the pressure applied is insufficient ${ }^{(20)}$. Regardless cementation, it was found that the highest statistically significant marginal gap values were recorded with E.max CAD, followed by Celtra Duo, while the lowest statistically significant marginal gap distance values were for VITA Suprinity. This was in agreement with some studies which proved that the E.max CAD specimens recorded higher vertical marginal gap mean values than that obtained with VITA Suprinity specimens ${ }^{(21)}$. This may be attributed to difficulties during restoration designing regarding scanning, digitization, and the milling process, milling burs size and the condition of the material during the milling procedure ${ }^{(22-24)}$. Some authors proved that the restorative material type affects the CAD-CAM performance regarding marginal adaptation ${ }^{(25)}$.

However, the results were not consistent with a study which found no significant difference when compared fitness of crowns made from $\mathrm{E}$ max $\mathrm{CAD}$ and the Vita Suprinity. Relating this result to the relative similarity in the chemical composition of both materials and similarity in post milling crystallization firing which was done in the same furnace at the same temperature for the same time. Thus they were exposed to same fabrication method from milling to firing process ${ }^{(26)}$.
Microleakage was evaluated after thermocycling using stereomicroscope. Among the types of ceramic veneers there are highly significant effect on microleakage. This comes to agreement with a study reported that there is a relationship between microleakage and the ceramic materials types relating that to the differences between the different ceramic types and the tooth in the coefficient of thermal expansion and contraction, That causes stress formation at the bond interface when the changes in temperature occur, leading to gap formation and hence microleakage ${ }^{(27)}$.

Regardless of measurement site, it was found that the highest statistically significant leakage values were recorded with IPS e.max CAD group followed by Celtra duo group while the lowest statistically significant leakage values were for VITA Suprinity group.

It was found that there is correlation between materials of lower marginal accuracy with that of higher microleakage. This was in accordance with a study related that to the hydrolytic effect of water on the resin cement under the impact of thermo-cycling which may be the cause of degradation of cement and hence microleakage ${ }^{(28)}$.

Irrespective of material type, cervical margin recorded statistically significant higher leakage mean values than incisal one. This finding is in agreement with another study ${ }^{(29)}$,which attributed that to the dentinal tubules orientation, which is perpendicular to the cervical margin. Their diameter and density is increased as a function of pulp proximity. Also, the enamel at the cervical margin is thinner than that of incisal margin, and the diameter and density of dentinal tubules decrease incisally. Another explanation is that the microleakage at the cervical area is related to contraction stresses induced due to the polymerization shrinkage of resin cement that lead to formation of gap at the weaker bond interface ${ }^{(30)}$. 


\section{CONCLUSION}

Under the test conditions, the following could be concluded:

- The type of veneer material affects both marginal accuracy and microleakage of laminate veneer restoration.

- Marginal gap of all types of laminate veneer enhanced by cementation.

\section{REFERENCES}

1. Hasan MB. 18 Months Follow Up of Diastemas Closure Using Ceramic Veneers Reinforced By Lithium Disilicate: A Case Report. J Dent Health Oral Disord Ther.2017; 8: 283-5.

2. Pini NP, Aguiar FH, Lima DA, Lovadino JR, Terada RS, Pascotto RC. Advances in dental veneers: materials, applications, and techniques.Clin Cosmet Investig Dent. 2012; 4: 9-16.

3. Rotoli BT, Lima D, Pini NP, Aguiar FH, Pereira GD, Paulillo LA. Porcelain Veneers as an Alternative for Esthetic Treatment:Clinical Report. Oper Dent. 2013:38:459-66.

4. Kelly JR, Benetti P. Ceramic materials in dentistry: Historical evolution and current practice. Aust Dent J. 2011;56:84-96.

5. Conrad HJ, Seong WL, Pesun IJ. Current ceramic materials and systems with clinical recommendations: a systematic review. J Prosthet Dent. 2007;98:389-404.

6. Giordano R, McLaren EA. Ceramics overview: classification by microstructure and processing methods. Compend Contin Educ Dent.2010;31:682-4.

7. Fasbinder DJ, Dennison JB, Heys D, Neiva G. A clinical evaluation of chairside lithium disilicate CAD/ CAM crowns: a two-year report. J Am Dent Assoc. 2010;141:10S-14S.

8. Balkaya MC, Cinar A, Pamuk S. Influence of firing cycles on the margin distortion of three all-ceramic crown systems. J Prosthet Dent. 2005;93:346-55.

9. Contrepois M, Soenen A, Bartala M, Laviole O. Marginal adaptation of ceramic crowns: A systematic review J Prosthet Dent. 2013;110:447-54.

10. Patel S, Saunders W, Burke FJT. Microleakage of dentin bonded crowns placed with different luting materials. Am J Dent. 1997;65:436-42.
11. Jacobs MS, Windeler AS. An investigation of dental luting cement solubility as a functional of the marginal gap. Journal of Prosthetic dent. 1992;65:436-42.

12. Tay FR, Pashley DH, Suh BI, Carvalho R, Itthagarun. A singlestep adhesives are permeable membranes. J Dent. 2002;30:371-82

13. Bedran AK, Cardoso PE, Ambrosano GM, Pimenta LA Thermal and mechanical load cycling on microleakage and shear bond strength to dentin. Oper Dent. 2004;29:42-8.

14. Piwowarczyk A, Laur HC, Sorensen JA. Microleakage of various cementing agents for full cast crowns. Dent Mater. $2005 ; 21: 445-53$

15. Andreatta Filho OD, Bottino MA, Nishioka RS, Valandro LF, Leite FP. Effect of thermocycling on the bond strength of a glass-infiltrated ceramic and a resin luting cement. J Appl Oral Sci. 2003;11:61-7.

16. Anusarice KJ, Kakar K, Ferree N. Which mechanical and physical testing methods are relevant for predicting the clinical performance of ceramic - based restoration. Oral Implants Res. 2007; 18: 218-31 .

17. Kohorst P, Dittaer MP, Borchers L. Influence of cyclic fatigue in water on the load-bearing capacity of dental bridge made of zirconia. Acta Biomater. 2008; 4: 1440 - 7 .

18. Quintas AF, Oliveira F, Bottino MA. Vertical marginal discrepancy of ceramic copings with different ceramic materials, finish lines, and luting agents: An in vitro evaluation . J Prosthet Dent. 2004;92:250-7.

19. Borges GA, Faria JS, Agarwal P, Spohr AM, Correr,Sobrinho L, Miranzi BA. In vitro marginal fit of three all ceramic crown systems before and after cementation. Oper Dent. 2012;37:641-9.

20. Al-Dwairi ZN, Alkhatatbeh RM, Baba NZ, Goodacre CJ. A comparison of the marginal and internal fit of porcelain laminate veneers fabricated by pressing and CAD-CAM milling and cemented with 2 different resin cements. J Prosthet Dent. 2019;121:470-6.

21. Basheer RR, Elsayed SM, Bahgat SF. Assessment OF accuracy of different CAD/CAM fabricated porcelain laminate veneers. Egy Dent J. 2017; 63:1841-55.

22. Rashad TM, Abdou AM. Fracture resistance of three different all-ceramic crown systems. Egy Dent J.2001; 47: 933.

23. Guazzato, M.,Albakry M., Simon P. Ringer, S. P., and Michael V. Swain, M. V.: Strength, fracture toughness and microstructure of a selection of all-ceramic materials. Part II. Zirconiabased dental ceramics. Dent Mater.2004; 20: 449-56. 
24. Fleming G J P., Nolan L., and Harris J. The in-vitro clinical failure of all-ceramic crowns and the connector area of fixed partial dentures: the influence of interfacial surface roughness. J. Dent.2005;33:405-12.

25. Papadiochou S, Pissiotis AL. Marginal adaptation and CAD-CAM technology: A systematic review of restorative material and fabrication techniques. J Prosthet Dent. 2018;119:545-51.

26. Majeed MA, Al-Adel SK. Evaluation of the marginal and internal fitness of full contour CAD/CAM crowns made from zirconia, lithium disilicate, zirconia-reinforced lithium silicate and hybrid dental ceramic by silicone replica technique (A comparative In vitro study). Jgerc. 2016; 4:10-20.
27. Hooshmand T, Mohajerfar M, Keshvad A, Motahhary P. Microleakage and marginal gap of adhesive cements for noble alloy full cast crowns. Oper Dent. 2011;36:258-65.

28. Aboushelib MN, Elmahy WA, Ghazy MH. Internal adaptation, marginal accuracy and microleakage of a pressable versus a machinable ceramic laminate veneers. J Dent. 2012; 40:670-7.

29. Andree P, Hans-Christoph L, John A. Microleakage of various cementing agents for full cast crowns. J Dent Mater. 2005; $21: 445-53$.

30. Chai SY, Bennani V, Aarts JM, Lyons K. Incisal preparation design for ceramic veneers: A critical review. J Am Dent Assoc. 2018;149:25-37. 